\title{
Surgical method of treatment and level of satisfaction with life among women diagnosed with breast cancer, according to time elapsed since performance of surgery
}

\author{
Elżbieta Cipora ${ }^{1, A-F}$, Magdalena Koniecznyy ${ }^{1, C-F}$, Irena Dorota Karwat ${ }^{1, E-F}$, Wojciech Roczniak ${ }^{1, C, F}$, \\ Magdalena Babuśka-Roczniak ${ }^{1, C, F}$ \\ 1 Jan Grodek State Higher Vocational School in Sanok, Poland \\ A - Research concept and design, B - Collection and/or assembly of data, C - Data analysis and interpretation, \\ $D$ - Writing the article, E-Critical revision of the article, $F$ - Final approval of article
}

\begin{abstract}
Cipora E, Konieczny M, Karwat ID, Roczniak W, Babuśka-Roczniak M. Surgical method of treatment and level of satisfaction with life among women diagnosed with breast cancer, according to time elapsed since performance of surgery. Ann Agric Environ Med. 2018 ; 25(3): 453-459. doi: $10.26444 /$ aaem/91586
\end{abstract}

\begin{abstract}
Introduction. In women diagnosed with breast cancer one of the methods most commonly applied in therapy is surgical treatment, which consists in a breast conserving surgery or total removal of the breast. The applied type of surgical treatment may exert an effect on the satisfaction with life of the women.

Objective. The aim of the study was evaluation of the satisfaction with life among women surgically treated for breast cancer, according to the type of surgery on the breast, and the time elapsed since its performance.

Materials and method. The study included 121 patients of the Sub-Carpathian Oncology Centre in Brzozów, south-east Poland, who had undergone surgical treatment due to breast cancer. The women expressed their informed consent to participate in the study. The method of a diagnostic survey was applied.

Results. The women obtained a mediocre result in satisfaction with life -5.64 sten scores. Patients who had undergone mastectomy had a considerably lower level of satisfaction with life, compared to those after breast-conserving surgery (4.73 sten scores vs. 6.30 sten scores). Evaluations of the satisfaction with life in the examined group significantly differed according to the time elapsed since performance of surgery.

Conclusions. There is a need for undertaking actions directed to women who have undergone surgical treatment for breast cancer within the period from 2-5 years, aimed at improving the satisfaction with life in this group of patients. In addition, special support should be provided for women who have undergone mastectomy, especially during the period of more than 1 and up to 2 years.
\end{abstract}

- Key words

breast cancer, surgical treatment, satisfaction with life

\section{INTRODUCTION}

Breast cancer is the most frequently diagnosed malignant cancer in women, and is a serious health and social problem. Annually, nearly 2 million cases of this cancer are diagnosed worldwide $[1,2,3]$. The type of therapy and its course depends, among other things, on the grade of advancement of the disease. Various methods are applied in the treatment of the women, defined as combined treatment, which covers systemic therapy and surgical treatment. At present, surgical treatment, which consists in the performance of breast conserving surgery or mastectomy, still remains the basic method of breast cancer treatment. Amputation of the breast may be performed simultaneously with its reconstruction, or delayed breast reconstruction, or may be combined with axillary lymph nodes dissection $[4,5]$. Breast-conserving surgery is currently the treatment method most frequently used in the United States and West European countries. This method of treatment covers diagnostic-therapeutic

Address for correspondence: Elżbieta Cipora, Jan Grodek State Higher Vocational School in Sanok, Mickiewicza 21, 38-500 Sanok, Poland

e-mail: elacipora@interia.pl

Received: 09.05.2018; accepted: 24.05.2018; first published: 11.06.2018 management concerning the breast and axillary lymph nodes, as well as radiotherapy $[6,7]$. Breast-conserving surgery is removal of the malignancy and a margin of normal tissue, and is performed in patients with the diagnosis of breast cancer Grades 1 or 2 of advancement of the disease [8]. Mastectomy is removal of the whole breast, often with the surrounding lymph nodes, and is performed when a woman is not qualified for conserving surgery, or does not express consent for this type of treatment. The types of amputation may be: simple mastectomy (removal of the breast without dissection of the axillary lymph nodes), modified radical mastectomy by Madden, Patey or Halsted, according to the grade of advancement of the breast cancer [5, 9]. When advanced cancer is diagnosed, the treatment consists in radiotherapy, chemotherapy and/or hormonal therapy [8].

Women diagnosed with breast cancer experience fear of losing a breast which is perceived as an attribute of femininity and sexuality, and fear of death. After surgical treatment for breast cancer, which is considered as the most effective method of therapy, the life of a woman changes in its all spheres. In women, especially those after mastectomy, a limitation in physical activity is observed, a change in their body image, and psychosocial consequences of treatment 
manifested, among others, by concern about the future, depression, the problem of being 'half-a-woman' [10-12]. Due to this, satisfaction with life in these women decreases. Today, satisfaction with life is considered as a measure of the quality of life and life satisfaction.

\section{OBJECTIVE}

Evaluation of the effect of the type of surgical treatment on satisfaction with life among women with breast cancer, with consideration of the time of performing the surgery.

\section{MATERIALS AND METHOD}

The study was conducted in the Sub-Carpathian Oncology Centre in Brzozów, south-east Poland, and included a group of 121 women diagnosed with breast cancer who had undergone surgical treatment. The women expressed their informed consent to participate in the study. The method of a diagnostic survey was used, and the research instrument was the Satisfaction With Life Scale (SWLS) by Diener et al. (1985), as adapted by Z. Juczyński (2001), and an authorconstructed questionnaire $[13,14]$.

The Satisfaction with Life Scale was used to depict satisfaction with own achievements and living conditions. It consisted of 5 statements, each assessed from 1-7 points. Satisfaction with life may be defined as a raw result within the range 5-35 points, or may be recalculated into standardized units in the sten scale according to the Polish norms for adults (Juczyński, 2001). The conversion of raw score into the sten scale was performed according to Polish norms for adults in which it was assumed that: 1 sten corresponds to the value of 5-9 of raw score, 2 stens - 10-11, 3 stens - 12-14, 4 stens - 15-17, 5 stens $-18-20,6$ stens $-21-23,7$ stens $-24-26,8$ stens $-27-28,9$ stens $-29-30$, and 10 stens $-31-35$ of the SWLS raw score [14]. The result 7-10 sten scores evidences high satisfaction with life, 5-6 sten scores - mediocre satisfaction, and 1-4 sten scores indicated low satisfaction with life. The higher the result, the higher the satisfaction with life. The author-questionnaire was used within the scope of 2 research problems, i.e. concerning the demographic situation and the social situation of the examined women. Statistical analyses were performed using statistical package SPSS v.17.0. Differences between groups were evaluated by non-parametric tests: Mann Whitney $U$ test and Kruskal Wallis test. The $\mathrm{p}$ value $\mathrm{p}<0.05$ was considered statistically significant.

\section{RESULTS}

The majority of respondents in the study group were women aged over $45(68.6 \%)$. Nearly $1 / 3$ of respondents were aged $25-45(31.4 \%)$. The percentage of women living in relationships was $63.6 \%$, whereas the remainder (36.4\%) were single. The education level of the examined women varied: the largest group $-52.9 \%$ of respondents, declared vocational or secondary school education, $31.4 \%$ - higher school education, while $15.7 \%$ of the women had primary school education level. The majority $-60.3 \%$ of respondents, were urban inhabitants, and $39.7 \%$ of the women lived in rural areas. $19.8 \%$ of the women evaluated their material standard as very good $36.4 \%$ - as good, whereas in the opinions of $43.8 \%$ of respondents their material standard was on a satisfactory level.

In the examined group, breast-conserving surgery was performed in $57.9 \%$ of the women, while mastectomy concerned the remaining $42.1 \%$ of respondents. The mean level of satisfaction with life according to the raw results for all respondents, was $20.67(\mathrm{SD}=4.63$; Median $=21.00)$. Women who had undergone mastectomy evaluated their satisfaction with life on the level 18.12 (SD = 3.70; Median $=18.00$ ), whereas those after breast-conserving surgery evaluated their satisfaction in considerably more positive terms, obtaining the raw result of $22.53(\mathrm{SD}=4.37$; Median $=23.00$ ).

A statistically significant difference in satisfaction with life was observed between the groups of women who had undergone radical surgery and breast-conserving surgery ( $\mathrm{p}<0.005$ ). According to the sten scale, the mean level of satisfaction with life for all women was $5.64(\mathrm{SD}=1.66$; Median $=6.00$ ). The group of women after mastectomy obtained the result of 4.73 sten scores $(\mathrm{SD}=1.25$; Median $=$ 5.00 ), while the group of women who had undergone breastconserving surgery, the result according to SWLS was 6.30 $(\mathrm{SD}=1.62$; Median $=6.00)$. Analysis of the values of the SWLS scale in individual statements confirmed that women after radical surgical treatment in each statement assessed their satisfaction with life more negatively than those who had breast-conserving surgery performed (Tab. 1).

The level of satisfaction with life of women was examined with consideration of the time elapsed since performance of the surgery. Among the respondents, 53 (43.80\%) had surgery performed within the period of up to 1 year. In the subsequent 45 women (37.19\%), the procedure was performed during the period of more than 1 year up to 2 years. In the smaller group - 23 women (9.01\%), 2-5 years had elapsed since the performance of surgery. The highest satisfaction with life - raw result 21.87, and according to the sten scale - 6.09, was obtained women who had undergone surgery in the period of more than 1 and up to 2 years. Women in whom the surgery had been recently performed, i.e. within the period of 1 year, assessed their satisfaction with life in the most negative terms and obtained raw result 20.85, and according to the sten scale -5.68 . In respondents who had undergone surgery $2-5$ years previously, satisfaction with life was: raw result 17.91, and sten scores -4.65 . The differences in the evaluation of satisfaction with life in the examined group, with consideration of the time elapsed since the performance of surgery were statistically significant: raw result $\mathrm{p}=0.003$; sten scores $-\mathrm{p}=0.002$ (Tab. 2).

Analysis of the results obtained by the women in the study in individual statements of the scale, showed considerable differences in the assessments of satisfaction with life. In the first statement, 'In most ways, my life is close to my ideal,' the mean SWLS value was 3.29 sten scores. The women who had undergone surgery $2-5$ years previously assessed their satisfaction with life below the mean value (2.70 sten scores), whereas those who had surgery performed within the period of up to 1 year, evaluated their satisfaction with life above the mean value (3.36 sten scores), while those who were 1-2 years after surgery (3.51 sten scores).

In the second statement, 'The conditions of my life are excellent', the mean satisfaction with life was evaluated on 
Table 1. Level of satisfaction with life among women after surgical treatment, with consideration of mastectomy and breast-conserving surgery

\begin{tabular}{|c|c|c|c|c|c|c|c|c|c|}
\hline \multirow{2}{*}{ Group } & \multirow{2}{*}{ Statistics } & \multirow{2}{*}{$\mathrm{N}$} & \multicolumn{2}{|c|}{ SWLS } & \multicolumn{5}{|c|}{ Statements in SWLS* } \\
\hline & & & Raw result & Result in sten scale & 1 & 2 & 3 & 4 & 5 \\
\hline \multirow{4}{*}{$\begin{array}{l}\text { Women after } \\
\text { mastectomy }\end{array}$} & Mean & \multirow{4}{*}{51} & 18.12 & 4.73 & 2.88 & 2.90 & 3.96 & 4.37 & 4.00 \\
\hline & SD & & 3.70 & 1.25 & 1.16 & 0.92 & 0.89 & 0.82 & 0.92 \\
\hline & Median & & 18.00 & 5.00 & 3.00 & 3.00 & 4.00 & 4.00 & 4.00 \\
\hline & Range & & $11.00-27.00$ & $2.00-8.00$ & $1.00-5.00$ & $1.00-5.00$ & $2.00-5.00$ & $3.00-6.00$ & $2.00-6.00$ \\
\hline \multirow{3}{*}{$\begin{array}{l}\text { Women after breast- } \\
\text { conserving surgery }\end{array}$} & SD & \multirow{3}{*}{70} & 4.37 & 1.62 & 1.11 & 1.00 & 0.87 & 0.89 & 1.08 \\
\hline & Median & & 23.00 & 6.00 & 4.00 & 4.00 & 5.00 & 5.00 & 5.00 \\
\hline & Range & & $11.00-30.00$ & $2.00-9.00$ & $1.00-5.00$ & $1.00-6.00$ & $3.00-7.00$ & $3.00-7.00$ & $3.00-7.00$ \\
\hline \multirow{3}{*}{ Total } & Mean & \multirow{3}{*}{121} & 20.67 & 5.64 & 3.29 & 3.31 & 4.50 & 4.82 & 4.74 \\
\hline & SD & & 4.63 & 1.66 & 1.18 & 1.02 & 0.99 & 0.94 & 1.19 \\
\hline & Range & & $11.00-30.00$ & $2.00-9.00$ & $1.00-5.00$ & $1.00-6.00$ & $2.00-7.00$ & $3.00-7.00$ & $2.00-7.00$ \\
\hline $\mathrm{p}$ & & & 0.000 & 0.000 & 0.001 & 0.000 & 0.000 & 0.000 & 0.000 \\
\hline
\end{tabular}

* 1 - In most ways my life is close to my ideal; 2 - The conditions of my life are excellent; 3 - I am satisfied with my life; 4 - So far, I have got the important things I want in life; 5 - If I could live my life over, I would change almost nothing

Table 2. Satisfaction with life among women who had undergone surgical treatment for breast cancer, with consideration of time elapsed since the performance of surgical procedure

\begin{tabular}{|c|c|c|c|c|c|c|c|c|c|}
\hline \multirow{2}{*}{$\begin{array}{l}\text { Time since } \\
\text { surgery }\end{array}$} & \multirow{2}{*}{ Statistics } & \multirow{2}{*}{$\mathrm{N}$} & \multicolumn{2}{|c|}{ SWLS } & \multicolumn{5}{|c|}{ Statements in SWLS* } \\
\hline & & & Raw result & Result in sten scale & 1 & 2 & 3 & 4 & 5 \\
\hline \multirow{4}{*}{ up to 1 year } & Mean & \multirow{4}{*}{53} & 20.85 & 5.68 & 3.36 & 3.38 & 4.51 & 4.85 & 4.75 \\
\hline & SD & & 4.46 & 1.58 & 1.16 & 0.92 & 0.93 & 0.93 & 1.16 \\
\hline & Median & & 22.00 & 6.00 & 4.00 & 3.00 & 5.00 & 5.00 & 5.00 \\
\hline & Range & & $12.00-29.00$ & $3.00-9.00$ & $1.00-5.00$ & $2.00-5.00$ & $3.00-6.00$ & $3.00-7.00$ & $3.00-7.00$ \\
\hline \multirow{3}{*}{$\begin{array}{l}\text { more than } 1 \\
\text { and up to } 2 \\
\text { years }\end{array}$} & SD & \multirow{3}{*}{45} & 4.89 & 1.79 & 1.14 & 1.14 & 1.02 & 1.01 & 1.23 \\
\hline & Median & & 21.00 & 6.00 & 3.00 & 3.00 & 5.00 & 5.00 & 5.00 \\
\hline & Range & & $11.00-30.00$ & $2.00-9.00$ & $1.00-5.00$ & $1.00-6.00$ & $3.00-7.00$ & $3.00-7.00$ & $3.00-7.00$ \\
\hline \multirow{3}{*}{$\begin{array}{l}\text { more than } 2 \\
\text { and up to } 5 \\
\text { years }\end{array}$} & Mean & \multirow{3}{*}{23} & 17.91 & 4.65 & 2.70 & 2.74 & 3.96 & 4.43 & 4.09 \\
\hline & SD & & 3.36 & 1.15 & 1.15 & 0.81 & 0.88 & 0.73 & 0.95 \\
\hline & Range & & $12.00-25.00$ & $3.00-7.00$ & $1.00-5.00$ & $1.00-4.00$ & $2.00-5.00$ & $3.00-6.00$ & $2.00-6.00$ \\
\hline \multirow{4}{*}{ Total } & Mean & \multirow{4}{*}{121} & 20.67 & 5.64 & 3.29 & 3.31 & 4.50 & 4.82 & 4.74 \\
\hline & SD & & 4.63 & 1.66 & 1.18 & 1.02 & 0.99 & 0.94 & 1.19 \\
\hline & Median & & 21.00 & 6.00 & 3.00 & 3.00 & 5.00 & 5.00 & 5.00 \\
\hline & Range & & $11.00-30.00$ & $2.00-9.00$ & $1.00-5.00$ & $1.00-6.00$ & $2.00-7.00$ & $3.00-7.00$ & $2.00-7.00$ \\
\hline$p$ & & & 0.003 & 0.002 & 0.025 & 0.008 & 0.007 & 0.045 & 0.004 \\
\hline
\end{tabular}

*1 - In most ways my life is close to my ideal; 2 - The conditions of my life are excellent; 3 - I am satisfied with my life; 4 - So far I have got the important things I want in life; 5 - If I could live my life over, I would change almost nothing

the level of 3.31 sten scores. The results obtained by the examined women qualified into individual time periods after the performance of surgery were close to the values obtained in the previous statement. The lowest satisfaction with life was obtained by women who had surgery performed 2-5 years ago (2.74 sten scores), followed by those who had undergone surgery within the period of up to 1 year $(3.38$ sten scores). The women in whom the surgery was performed within the period of more than 1 up to 2 years, evaluated their satisfaction in this statement on the level of 3.53 sten scores.

In the third statement, 'I am satisfied with my life,' the mean result of satisfaction with life was 4.50 sten scores. The highest result (4.78 sten scores) in this statement was obtained by women who had undergone surgery more than 1 and up to 2 years ago, while the lowest result (3.96 sten scores) by those who had surgery performed $2-5$ years previously.

In the fourth statement, 'So far, I have got the important things I want in life' the mean satisfaction with life in the examined group was 4.82 sten scores. The women who had surgery performed within the period of more than 1 and up to 2 years, obtained the highest result of 4.98 sten scores, and a slightly lower result 4.85 sten scores was obtained by the respondents who had undergone surgery within the period of up to 1 year. In turn, the women in whom more than 2 and up to 5 years had elapsed since surgery, obtained in this statement the result 4.43 sten scores. 
In the fifth statement, 'If I could live my life over, I would change almost nothing' the respondents obtained the mean result concerning their satisfaction with life -4.74 sten scores. In this statement, similar to the previous one, the highest evaluations -5.07 sten scores were obtained by women who had surgery performed within the period of more than 1 and up to 2 years, while the lowest - those in whom $2-5$ years had elapsed since surgery - 4.09 sten scores (Tab. 2).

Statistically significant differences $(\mathrm{p}<0.005)$ were observed in individual statements in the SWLS scale according to the time elapsed since the performance of surgery in the examined group (Tab. 2).

The level of the women's satisfaction with life was also analyzed according to the type of surgery and time elapsed from its performance (Tab. 3). Women after mastectomy, in whom the time since surgery was not longer than 1 year, obtained the mean result of satisfaction with life of 5.00 sten scores (raw result - 19.00), whereas women who had undergone breast-conserving therapy evaluated their level of satisfaction higher - 6.13 sten scores (raw result - 22.06; $\mathrm{p}=0.027$ ). In the first and second statements, no statistically significant relationships were found between the examined groups. However, in statement 3 - 'I am satisfied with my life', a statistically significant relationship was observed ( $\mathrm{p}=$ 0.041). In the subsequent, fourth statement - 'So far I have got the important things I want in life' and in the fifth statement - 'If I could live my life over, I would change almost nothing', there occurred statistically confirmed relationships ( $\mathrm{p}=0.030$ and $\mathrm{p}=0.000$, respectively). In addition, in all statements, the women who had undergone breast-conserving surgery obtained a higher level of satisfaction with life. Table 3 shows detailed results obtained by the examined women in individual statements of the scale.

Women who had undergone mastectomy during the period of more than 1 and up to 2 years evaluated their level of satisfaction with life considerably more negatively, compared to those who had breast-conserving surgery performed $(\mathrm{p}=0.000)$. In individual statements of the scale, the women after breast-conserving surgery obtained higher results than those after mastectomy. Also, statistically significant relationships were observed in the following statements: Statement $1-\mathrm{p}=0.035$; Statement 2- $\mathrm{p}=0.011$; Statements 3,4 and $5-p=0.000$. Women who had undergone surgery within the period from $2-5$ years after mastectomy evaluated

Table 3. Satisfaction with life among women after surgical treatment for breast cancer with consideration of the type of surgery and time elapsed since its performance

\begin{tabular}{|c|c|c|c|c|c|c|c|c|c|c|}
\hline \multirow{2}{*}{$\begin{array}{l}\text { Time after } \\
\text { surgery }\end{array}$} & \multirow{2}{*}{$\begin{array}{l}\text { Type of } \\
\text { surgery }\end{array}$} & \multirow{2}{*}{ Statistics } & \multirow{2}{*}{$\mathrm{N}$} & \multicolumn{2}{|c|}{ SWLS } & \multicolumn{5}{|c|}{ Statements in SWLS* } \\
\hline & & & & raw result & sten score & 1 & 2 & 3 & 4 & 5 \\
\hline \multirow{8}{*}{ up to 1 year } & \multirow{4}{*}{$M^{* *}$} & Mean & \multirow{4}{*}{21} & 19.00 & 5.00 & 3.24 & 3.14 & 4.14 & 4.48 & 4.00 \\
\hline & & SD & & 4.04 & 1.30 & 1.14 & 0.91 & 0.96 & 0.87 & 0.89 \\
\hline & & Median & & 19.00 & 5.00 & 3.00 & 3.00 & 5.00 & 5.00 & 4.00 \\
\hline & & Range & & $12.00-24.00$ & $3.00-7.00$ & $1.00-5.00$ & $2.00-5.00$ & $3.00-5.00$ & $3.00-6.00$ & $3.00-5.00$ \\
\hline & \multirow{4}{*}{$B C^{* * *}$} & SD & \multirow{3}{*}{32} & 4.36 & 1.60 & 1.19 & 0.92 & 0.84 & 0.89 & 1.05 \\
\hline & & Median & & 22.00 & 6.00 & 4.00 & 4.00 & 5.00 & 5.00 & 5.00 \\
\hline & & Range & & $14.00-29.00$ & $3.00-9.00$ & $1.00-5.00$ & $2.00-5.00$ & $3.00-6.00$ & $4.00-7.00$ & $4.00-7.00$ \\
\hline & & $\mathrm{p}$ & & 0.027 & 0.016 & 0.514 & 0.138 & 0.041 & 0.030 & 0.000 \\
\hline \multirow{8}{*}{$\begin{array}{l}\text { more than } 1 \\
\text { and up to } 2 \\
\text { years }\end{array}$} & \multirow{3}{*}{$M^{* *}$} & Mean & \multirow{3}{*}{15} & 18.27 & 4.08 & 3.00 & 2.95 & 4.00 & 4.20 & 4.13 \\
\hline & & Median & & 18.00 & 5.00 & 3.00 & 3.00 & 4.00 & 4.00 & 4.00 \\
\hline & & Range & & $11.00-27.00$ & $2.00-8.00$ & $1.00-5.00$ & $1.00-5.00$ & $3.00-5.00$ & $3.00-6.00$ & $3.00-6.00$ \\
\hline & \multirow{5}{*}{$B C^{* * *}$} & Mean & \multirow{4}{*}{30} & 23.67 & 6.73 & 3.77 & 3.83 & 5.17 & 5.37 & 5.53 \\
\hline & & SD & & 4.40 & 1.64 & 1.04 & 1.09 & 0.91 & 0.81 & 1.04 \\
\hline & & Median & & 24.00 & 7.00 & 4.00 & 4.00 & 5.00 & 5.00 & 5.50 \\
\hline & & Range & & $11.00-30.00$ & $2.00-9.00$ & $1.00-5.00$ & $1.00-6.00$ & $3.00-7.00$ & $3.00-7.00$ & $3.00-7.00$ \\
\hline & & $\mathrm{p}$ & & 0.000 & 0.000 & 0.035 & 0.011 & 0.000 & 0.000 & 0.000 \\
\hline \multirow{8}{*}{$\begin{array}{l}\text { more than } 2 \\
\text { and up to } 5 \\
\text { years }\end{array}$} & \multirow{4}{*}{$M^{* *}$} & Mean & \multirow{4}{*}{15} & 16.73 & 4.27 & 2.27 & 2.53 & 3.67 & 4.40 & 3.87 \\
\hline & & SD & & 2.89 & 0.96 & 0.96 & 0.74 & 0.90 & 0.63 & 0.83 \\
\hline & & Median & & 17.00 & 4.00 & 2.00 & 3.00 & 4.00 & 4.00 & 4.00 \\
\hline & & Range & & $12.00-23.00$ & $3.00-6.00$ & $1.00-4.00$ & $1.00-4.00$ & $2.00-5.00$ & $3.00-5.00$ & $2.00-5.00$ \\
\hline & \multirow{4}{*}{$B C^{* * *}$} & Mean & & 20.13 & 5.38 & 3.50 & 3.13 & 4.50 & 4.50 & 4.50 \\
\hline & & Median & & 19.00 & 5.00 & 4.00 & 3.00 & 4.50 & 4.50 & 4.00 \\
\hline & & Range & & $17.00-25.00$ & $4.00-7.00$ & $2.00-5.00$ & $2.00-4.00$ & $4.00-5.00$ & $3.00-6.00$ & $3.00-6.00$ \\
\hline & & $\mathrm{p}$ & & 0.034 & 0.047 & 0.017 & 0.112 & 0.029 & 0.805 & 0.207 \\
\hline
\end{tabular}

* 1 - In most ways my life is close to my ideal; 2 - The conditions of my life are excellent; 3 - I am satisfied with my life; 4 - So far I have gotten the important things I want in life; 5 - If I could live my life over, I would change almost nothing 
their level of satisfaction with life at 4.27 sten scores (16.73 - raw result), whereas those who had breast-conserving surgery performed at the same time obtained the level of satisfaction with life on the level of 5.38 sten scores (20.13 raw result). Both with respect to raw result and sten scale, a statistically significant relationship was found $(\mathrm{p}<0.005)$. In all 5 statements of the SWLS, women who had undergone breast-conserving surgery evaluated their satisfaction with life higher than those after mastectomy. In Statements 1 and 3, statistically significant relationships were observed between the 2 groups ( $\mathrm{M}$ and $\mathrm{BC}$ ) within the same time interval $-\mathrm{p}=0.017 ; \mathrm{p}=0.029$ (Tab. 3).

Satisfaction with life is the reflection of human functioning from the biological, psychological and social aspects. Its level may be affected by, among others, state of health, social support, family situation, and social status. Satisfaction with life itself may also be an element strengthening a woman in the struggle with the cancerous disease.

\section{DISCUSSION}

The treatment of women suffering from breast cancer results in certain limitations in their physical and psychological functioning. Due to these limitations, the women have a decreased satisfaction with life and experience fear related with the diagnosed disease and the future. The type of surgical treatment applied exerts an effect on the level of satisfaction with the life of the ill women. In own study, it was confirmed that respondents who had undergone breastconserving surgery had a higher level of satisfaction with life than those after radical surgery (6.30 vs. 4.73 sten scores). Undoubtedly due to the smaller extent of surgery, the women functioned better in daily life. Similar results were obtained in the studies by Han et al. and He et al. who found that women after breast-conserving surgery had a higher level of satisfaction with life, compared to those after mastectomy and/or reconstruction of the breast $[15,16]$. According to Zegarski et al., in women after mastectomy the greatest deterioration of functioning takes place in the physical and social spheres, and these spheres are the most visible, and to a considerable degree may exert an effect on the perceived satisfaction with life [17].

At present, breast-conserving surgery is the most frequently used method of surgical treatment of breast cancer. According to various researchers, surgeries of this type consist of more than $70 \%$ of all procedures of surgical treatment applied in breast cancer $[7,18,10,19]$. Considering the effectiveness of treatment, breast-conserving surgery is equally as effective as mastectomy from the oncologic aspect [20]. At present, considerable progress may be observed in surgical techniques and, therefore, even in the case of large tumours, breast-conserving surgery may be successfully applied [21]. However, many literature reports show that despite the above-mentioned facts, women diagnosed with breast cancer, in the situation of the possibility to choose the type of surgical treatment, most frequently decide on mastectomy rather than breast-conserving surgery [22, 23, 24]. Perhaps, the reason for such a decision is fear of the recurrence of cancer, and complete recovery becomes most important. A systematic increase in the number of mastectomy procedures performed may be observed worldwide $[25,26]$. In a study of a group of 701 patients after surgical treatment for breast cancer (349 after radical mastectomy by Halsted, 352 after breast-conserving surgery), Veronesi et al. observed that the long-term survival of women after breast-conserving surgery and radical surgery was the same [27].

According to many researchers, there is no relationship between the quality of life and the type of surgical treatment of breast cancer applied $[28,15,29]$. In their study, Miśkiewicz et al. confirmed that women after mastectomy who decided against breast reconstruction had a decreased quality of life, and consequently, satisfaction with life [30]. A high satisfaction with life is translated into high quality of life and vice versa. The study by Han et al. showed that women who had undergone breast-conserving surgery had a higher quality of life and satisfaction with life than those after mastectomy and breast reconstruction [15].

In own study, the level of satisfaction with life of women after surgical treatment for breast cancer depended on the time elapsed since performance of the surgery. The highest satisfaction - 6.09 sten scores, was observed in women who had surgery performed within the period of more than 1 and less than 2 years previously, whereas the lowest satisfaction 4.65 sten scores, the women who had undergone surgery $2-5$ years previously. The patients in whom the time elapsed since surgical treatment was the shortest - up to 1 year, evaluated their satisfaction at 5.68 sten scores. Also, statistically significant differences were observed in individual statements of the SWLS with consideration of time elapsed since the performance of breast surgery.

In the study by Szczepańska-Gieracha et al., conducted among participants of a rehabilitation camp in whom the mean time since the performance of breast surgery was 6.8 years, no recurrence of cancer was observed in any of the examined women. The mean raw result according to the SWLS was $19.0(\mathrm{SD}=4.70)$. Satisfaction with life in the group of women who had surgery performed within the period of up to 5 years was $17.9(\mathrm{SD}=4.0)$, and in the group of women who had undergone such a surgery within the period longer than 5 years, was $20.2(\mathrm{SD}=5.2)$. It should be added that women from Group II were by 8 years older, on average, than those who had undergone surgery within the period of up to 5 years. In healthy women, it is the opposite, because the level of life satisfaction decreases with age [31]. In the same study, Szczepańska-Gieracha et al. reported that they examined the quality of life using the scale for assessment of satisfaction with life. A decrease was found in the intensity of constructive strategies (positive revaluation and the fighting spirit); however, no decrease was observed in the intensity of destructive strategies [31]. This may indicate the necessity to adjust therapeutic actions addressed to women with breast cancer to the stage of struggle with the cancerous disease.

Olsson et al. confirmed that in women 1 month after surgical breast procedure preceded by chemotherapy, satisfaction with life was associated mainly with social support and the current state of health [32]. These results indicate a great need for the enhancement of social support in the area of psychological and cognitive functioning of patients.

Mastectomy due to breast cancer results in the occurrence in women of problems of a psychological nature. In the study conducted by Arroyo and Lopez in a group of 46 women, it was proved that changes in the body self-image caused in women after mastectomy, the sense of loss of attractiveness, low self-esteem, and avoidance of contact with the surroundings, as well as the feeling of mutilation 
and loss of the attribute of femininity and sexuality, which cannot be replaced [33]. Similarly, Karabulut and Erci, while examining women after mastectomy, found that their level of satisfaction with marital life was low [34]. This could result from the fact that after this type of surgery the women felt uncomfortable due to the mutilation of the body. Klassen et al. confirmed that breast surgery and the state of the breast after surgery are the factors which decrease the satisfaction of women with: the image of the breast, overall result of surgery, good psycho-social wellbeing, satisfaction with sexual life, psychological health and satisfaction with care [35].

The study by Wei et al. showed that women who had undergone breast-conserving surgery functioned significantly better statistically in the psycho-social and sexual spheres, compared to those who had undergone mastectomy and breast reconstruction [36].

The study by Agarwal et al., conducted in 2 groups of women - after mastectomy without breast reconstruction and after mastectomy with breast reconstruction - found that $76.0 \%$ of women in the group of respondents after breast reconstruction were very satisfied with their physical functioning. However, in the group of women after mastectomy, only $20.0 \%$ of respondents were satisfied with functioning after the surgery. At the same time, in this study it was confirmed that mastectomy with a simultaneous reconstruction of the breast decreased the risk of disorders in the psychological sphere, and should be recommended to all women after breast amputation who have no contraindications against this type of surgical management [37].

It may be presumed that an intensification of symptoms in the areas of psychological functioning depends on the type of surgery. This was confirmed by the study by Dragomir et al. who proved that patients after breast-conserving surgery had the less disturbed functioning in the psychological sphere [38]. In the study by Asuzu and Efosa-Urhoghide, attention was paid to the fact that psycho-social factors were strong predictors of satisfaction with life in a group of married women diagnosed with breast cancer [39]. In the study by Kelsall et al., it was found that women after breast-conserving surgery regained their health more quickly, presented a better psycho-social functioning and a higher self-evaluation, compared to women who had undergone mastectomy with a simultaneous breast reconstruction [40].

The study by Montebarocci et al. conducted in Bologna, Italy, among 62 women ( 43 after mastectomy and 19 who were healthy), showed that the women after mastectomy, even after breast reconstruction, reported a higher level of anxiety and higher dissatisfaction with the body self-image than those who were healthy [41]. According to the researchers, this may indicate excessively high expectations of patients concerning the effect of the breast reconstruction procedure.

In the presented study, women who had undergone breastconserving surgery, in each of the statements according to SWLS, evaluated their satisfaction with life in more positive terms, compared to the women who had mastectomy performed. Considering the type of surgery and the time elapsed since performance of the procedure, in own study it was found that women who had undergone breast-conserving surgery also obtained higher results in each of the statements of the SWLS than those after mastectomy.

In up-to-date literature, it is difficult to find reports concerning results obtained by respondents examined using the SWLS in individual statements of this scale.

\section{CONCLUSIONS}

1. Women who had undergone breast-conserving surgery, according to the SWLS, obtained a mean result of 6.30 sten scores, which evidences high satisfaction with life. However, women who had mastectomy performed obtained a mean result on the level of 4.73 sten scores, which indicates a considerably lower satisfaction with life.

2. Time elapsed since the performance of surgery was statistically significantly important for the level of satisfaction with life of women with breast cancer. Women who had undergone surgery within the period of more than 1 and up to 2 years obtained the highest result according to the SWLS - 6.09 sten scores, whereas those in whom the time since the performance of surgery was longer $-2-5$ years, assessed their satisfaction with life in considerably more negative terms and obtained the result of 4.65 sten scores.

3. Women who had undergone breast-conserving surgery evaluated their satisfaction with life higher than those who had undergone breast-conserving surgery within the period of more than 1 and up to 2 years, obtained the highest result according to the sten scale -6.73 , whereas the lowest evaluations were reported by respondents who had undergone mastectomy within the period of more than 1 and up to 2 years -4.08 sten scores.

4. There is a need for undertaking actions directed to women who have undergone surgical treatment for breast cancer within the period from $2-5$ years, aimed at improving the satisfaction with life in this group of patients. In addition, special support should be provided for women who have undergone mastectomy, especially during the period of more than 1 and up to 2 years.

\section{REFERENCES}

1. Ferlay J, Soerjomataram I, Dikshit R, et al. Cancer incidence and mortality worldwide: sources, methods and major patterns in GLOBOCAN 2012. Int J Cancer. 2015; 136: 359-386.

2. Ginsburg O, Bray F, Coleman MP. The global burden of women's cancers: a grand challenge in global health. The Lancet. 2017; 389: $847-860$.

3. Harbeck N, Gnant M. Breast cancer. Lancet. 2017; 389: 1134-1150.

4. Jassem J, Krzakowski M (ed). Rak piersi. Via Medica. Gdańsk 2013.

5. Jeziorski A., Rutkowski P (ed.) Kompendium Chirurgii Onkologicznej. Via Media. Gdańsk 2014.

6. Murawa P, Murawa D, Adamczyk B, Połom K. Breast cancer: Actual methods of treatment and future trends. Rep Pract Oncol Radiother. 2014; 19: 165-172.

7. Senkus E, Kyriakides S, Penault-Llorca F, Poortmans P, Thompson A, Zackrisson S, Cardoso F. Primary breast cancer: ESMO Clinical Practice Guidelines for diagnosis, treatment and follow-up. Ann Oncol. 2013; 24: vi7-vi23, https://doi.org/10.1093/annonc/mdt284.

8. Masoud V, Pagès G. Targeted therapies in breast cancer: New challenges to fight against resistance. World J Clin Oncol. 2017; 8: 120-134.

9. Etchegary H, Dicks E, McCrate F, Powell E, Chafe J, Roome R, Simmonds C. Breast cancer surgical treatment choices in Newfoundland and Labrador, Canada: Patient and surgeon perspectives. J Public Health Res. 2017; 6(2): 867. doi: 10.4081/jphr.2017.867.

10. Guyomard V, Leinster S, Wilkinson M. Systematic review of studies of patients satisfaction with breast reconstruction after mastectomy. Breast. 2007; 16: 547-567.

11. Kovac A, Petrović SP, Nedeljković M, Kojić M, Tomić S. Post-operative condition of breast cancer patients from standpoint of psycho-oncologypreliminary results. Med Pregl. 2014; 67: 43-48.

12. Piot-Ziegler C, Sassi ML, Raffoul W, Delaloye JF. Mastectomy, body deconstruction, and impact on identity: a qualitative study. Br J Health Psychol. 2010; 15: 479-510. 
13. Diener E, Emmons RA, Larson RJ, Griffin S. The satisfaction with life scale. J Pers Assess. 1985; 49: 71-75.

14. Juczyński Z. Narzędzia pomiaru w promocji i psychologii zdrowia. Pracownia Testów Psychologicznych Polskiego Towarzystwa Psychologicznego. Warszawa 2001.

15. Han J, Grothuesmann D, Neises M, Hille U, Hillemanns P. Quality of life and satisfaction after breast cancer operation. Arch Gynecol Obstet. 2010; 282: 75-82.

16. He ZY, Tong Q, Wu SG, Li FY, Lin HX, Guan XX. A comparison of quality of life and satisfaction of women with early-stage breast cancer treated with breast conserving therapy vs. mastectomy in southern China. Support Care Cancer. 2012; 20: 2441-2449.

17. Zegarski W, Głowacka I, Ostrowska Ż. Ocena jakości życia kobiet po mastektomii na podstawie standardowych kwestionariuszy: QLQ-C30 i QLQ-BR23. Nowotwory. Journal of Oncology. 2010; 60: 532-535.

18. Fitzal F, Gnant M. Breast conservation: evolution of surgical strategies. Breast J. 2006; 12: 165-73.

19. Heil J, Fuchs V, Golatta M, Schott S, Wallwiener M, Domschke C, Sinn P, Lux MP, Sohn C, Schütz F. Extent of Primary Breast Cancer Surgery: Standards and Individualized Concepts. Breast Care. 2012; 7(5): 364-369.

20. Litière S, Werutsky G, Fentiman IS, Rutgers E, Christiaens MR, Van Limbergen E, Baaijens MH, Bogaerts J, Bartelink H. Breast conserving therapy versus mastectomy for stage I-II breast cancer: 20 year followup of the EORTC 10801 phase 3 randomised trial. Lancet Oncol. 2012; 13(4): 412-419.

21. Hamdi M, Sinove Y, DePypere H, Van Den Broucke R, Vakaet L, Cocquyt V, Villeirs G, Lambein C, Van Maele G. The role of oncoplastic surgery in breast cancer. Acta Chir Belg. 2008; 108(6): 666-72.

22. Habermann EB, Abbott A, Parsons HM, Virnig BA, Al-Refaie WB, Tuttle TM. Are mastectomy rates really increasing in the United States? J Clin Oncol. 2010; 28(21): 3437-3441.

23. Throckmorton AD, Esserman LJ. When Informed, All Women Do Not Prefer Breast Conservation. J Clin Oncol. 2009; 27(4): 484-486.

24. Vanderwalde LH, Edge SB. Decision shared or otherwise: the ongoing evolution of local therapy for breast cancer. J Clin Oncol. 2014; 32(9): 873-5.

25. Balch CM, Jacobs LK. Mastectomies on the Rise for Breast Cancer: The Tide Is Changing. Ann Surg Oncol. 2009; 16(10): 2669-2672.

26. Lee MC, Rogers K, Griffith K, Diehl KA, Breslin TM, Cimmino VM, Chang AE, Newman LA, Sabel MS. Determinants of breast conservation rates: reasons for mastectomy at a comprehensive cancer center. Breast J. 2009; 15(1): 34-40.

27. Veronesi U, Cascinelli N, Mariani L, Greco M, Saccozzi R, Luini A, Aguilar M, Marubini E. Twenty-year follow-up of a randomized study comparing breast-conserving surgery with radical mastectomy for early breast cancer. N Engl J Med. 2002; 347(16): 1227-32.

28. Szadowska-Szlachetka Z, Stanisławek A, Charzyńska-Gula M, Kachaniuk H, Muzyczka K, Kocka K. Differences in the quality of life of women before and after breast reconstruction measured with the use of EORTC QLQ-C 30 and EORTC QLQ-BR 23 scale. Przegląd Menopauzalny. 2013; 17 (3): 254-259.

29. Sio TT, Chang K, Jayakrishnan R, Wu D, Politi M, Malacarne D, Saletnik $\mathrm{J}$, Chung M. Patient age is related to decision-making, treatment selection, and perceived quality of life in breast cancer survivors. World J Surg Oncol. 2014; 12: 230; doi: 10.1186/1477-7819-12-230.

30. Miśkiewicz H, Antoszewski B, Woźniak E, Iljin A. Satisfaction with Life and Social Factors in Decision-Making Proces on Breast Reconstruction in Women after Mastectomy. Pol Przegl Chir. 2016; 88: 270-276.

31. Szczepańska-Gieracha J, Malicka I, Rymaszewska, Woźniewski M. Przystosowanie psychologiczne kobiet bezpośrednio po operacji onkologicznej i po zakończonym leczeniu. Współcz Onkol. 2010; 14: 403-410.

32. Olsson M, Nilsson M, Fugl-Meyer K, Petersson LM, Wennman-Larsen A, Kjeldgård L, Alexanderson K. Life satisfaction of women of working age shortly after breast cancer surgery. Quality Life Res. 2017; 26: 673-684.

33. Arroyo JMG, López MLD. Psychological Problems Derived from Mastectomy: A Qualitative Study. Int J Surgical Oncol. 2011; 2011: 132461-132470.

34. Karabulut N, Erci B. Sexual desire and satisfaction In: Sexual life affecting factors in breast cancer survivors after mastectomy. J Psychosoc Oncol. 2009; 27: 333-343.

35. Klassen AF, Pusic AL, Scott A, Klok J, Cano SJ. Satisfaction and quality of life in women who undergo breast surgery: a qualitative study. BMC Womens Health. 2009; 9:11, doi: 10.1186/1472-6874-9-11.

36. Wei CH, Scott AM, Price AN, Miller HC, Klassen AF, Jhanwar SM, Mehrara BJ, Disa JJ, McCarthy C, Matros E, Cordeiro PG, Sacchini V, Pusic AL. Psychosocial and Sexual Well-Being Following NippleSparing Mastectomy and Reconstruction. Breast J. 2016; 22(1): 10-17.

37. Agarwal P, Patel AK, Saxena A, Mishra A. Assessment of Quality of Life after Breast Reconstructive Surgery Following. Mastectomy for Carcinoma Breast. J Surg Pakistan. 2011; 16(2): 50-55.

38. Dragomir BI, Fodoreanu I, Rancea A. The impact of depression and anxiety on the quality of life in nonmetastatic breast cancer patients in postoperative evaluation. Clujul Med. 2013; 86: 48-52.

39. Asuzu C, Efosa-Urhoghide N. Psychosocial predictors of life satisfaction among married women with breast cancer. Am Ass Cancer Res. 2017; 77: pp. 2765.

40. Kelsall JE, McCulley SJ, Brock L, Akerlund MTE, Macmillan RD. Comparing oncoplastic breast conserving surgery with mastectomy and immediate breast reconstruction: Case-matched patient reported outcomes. J Plast Reconstr Aesthet Surg. 2017; 70(10): 1377-1385.

41. Montebarocci O, Lo Dato F, Baldaro B, Morselli P, Rossi NC. Anxiety and body satisfaction before and six months after mastectomy and breast reconstruction surgery. Psychol Rep. 2007; 101(1): 100-106. 